\title{
Influence of Diatomite and Mineral Powder on Thermal Oxidative Ageing Properties of Asphalt
}

\author{
Yongchun Cheng, ${ }^{1}$ Jinglin Tao, ${ }^{1}$ Yubo Jiao, ${ }^{1}$ Qinglin Guo, ${ }^{2}$ and Chao $\mathrm{Li}^{1}$ \\ ${ }^{1}$ College of Transportation, Jilin University, Changchun, Jilin 130025, China \\ ${ }^{2}$ School of Civil Engineering, Hebei University of Engineering, Handan, Hebei 056038, China \\ Correspondence should be addressed to Qinglin Guo; gqlhbue@163.com
}

Received 12 May 2015; Revised 25 July 2015; Accepted 29 July 2015

Academic Editor: Peter Majewski

Copyright (c) 2015 Yongchun Cheng et al. This is an open access article distributed under the Creative Commons Attribution License, which permits unrestricted use, distribution, and reproduction in any medium, provided the original work is properly cited.

Ageing of asphalt affects the performances of asphalt pavement significantly. Therefore, effects of diatomite and mineral powder on ageing properties of asphalt were investigated systematically in order to improve the antiageing property of mixture. Thin film oven test (TFOT) was used to conduct the short term ageing in laboratory. Softening points, penetrations, force ductility, low temperature creep properties, and viscosities of asphalt mastics were tested before and after TFOT, respectively. Results indicated that percent retained penetration (PRP) increased with the increasing of fillers. Increment of softening point $(\Delta T)$, ductility retention rate (DRR), deformation energy ageing index (JAI), and viscosity ageing index (VAI) of asphalt mastics nonlinearly decreased with the increasing of fillers. Ageing of asphalt was reduced by diatomite and mineral powder. And the antiageing effect of diatomite was better than that of mineral powder as a result of its porous structure. It is suggested that the mineral powder could be reasonably replaced by diatomite in order to reduce thermal oxidative ageing of asphalt mixture. The optimal content of diatomite $12.8 \%$ is also suggested for engineering.

\section{Introduction}

Asphalt pavement has been developed rapidly for its good performance in the world [1]. Asphalt ageing occurs during the constructing and service procedure of asphalt pavement. Viscosity of asphalt increases with the growing of ageing time. Finally, asphalt turns into brittle material gradually [2]. Though ageing hardening of asphalt enhances the rutting resistance, low temperature property of asphalt pavement is also reduced by hardening [1]. This will result in pavement cracks and reduced the comfortableness of driving [3]. Thus, the ageing hardening of asphalt has significant impact on pavement. It is necessary to find the solution which can improve the antiageing property of asphalt.

A number of modifiers have been widely used to improve the properties of asphalt and/or mixture [4-8]. And diatomite is an inorganic modifier. It is a sedimentary rock, white or light yellow in color, composed of the fossilized skeletons of diatoms, one celled algae-like plant which accumulates in marine or lacustrine environments [9]. The skeletons are commonly composed of amorphous silica (silicon dioxide, $\mathrm{SiO}_{2}$ ), carbonate, clay minerals, quartz, and feldspars. Diatomite has the high absorptive capacity and surface area, chemical stability, and low bulk density due to its honeycomb silica structures of diatom skeletons [10]. It is also called diatomaceous earth or organogenetic sedimentary rock. Kietzman and Rodier [11] studied the performance of diatomite modified asphalt concrete firstly. They indicated that the high temperature deformation resistance of asphalt mixture was improved. Cong et al. [12] investigated the physical, chemical, and dynamic rheological properties of diatomite modified asphalt. The results showed that viscosity of asphalt increased with the increasing of diatomite. And the effect of diatomite on low temperature performance was not evident. Song et al. [13] studied the interactive mechanism of diatomite and asphalt. Their results suggested that diatomite particle had a porous structure which could effectively adsorb small molecules and low polar aromatic molecules. And diatomite particle formed a lot of anchorage points in asphalt. Tan et al. $[14,15]$ evaluated thermodynamics and chemical 
and dynamic mechanical properties of diatomite modified asphalt and mixtures. Their results showed that diatomite modified mixture had better low temperature performance than the control mixture, and the critical bending and compressive strain energy densities of modified mixture were all greater than that of the control mixture. Cheng et al. [16] indicated that diatomite improved the impact of resistance significantly and weakens the temperature susceptibility. Recently, Guo et al. [17] studied the properties of diatomiteglass fiber modified mixture. Their results indicated that diatomite had a significant effect on the stiffness modulus of asphalt mixture; the compound modified mixture had better travelling performance than the control mixture. Thus, it can be found that diatomite is beneficial for the improvement of mixture properties [11, 12, 15, 17]. Furthermore, Lu and Isacsson [2] and Qin et al. [18] also indicated that ageing hardening of asphalt was closely correlated and attributed to the compositional changes within asphalts, which involves the conversion of aromatics into asphaltenes and an increase in total pericondensed aromaticity and carbonyl and sulfoxide functional groups. Porous structure of diatomite could adsorb the small molecules group effectively [13]. Thus, the ageing reaction may be reduced by diatomite. Though above research groups have studied the effects of diatomite on the road properties of asphalt and mixtures, the influence of diatomite on thermal oxidative ageing properties of asphalt has not been studied systematically. It is meaningful to investigate the effect of diatomite on the ageing performance of asphalt in order to reduce the ageing during the using process of pavement. This will also provide a reference for the application of diatomite modified asphalt mixture.

Therefore, thin film oven test (TFOT) was used to simulate the short term ageing process in order to study the impact of diatomite on the ageing property of asphalt. Effect of mineral powder on ageing property was also investigated, for determining the difference between diatomite and mineral powder. Diatomite asphalt mastics (DA) and mineral powder asphalt mastics (MA) were prepared using high-shear homogenizer. Properties of both mastics such as penetration, softening point, force ductility, low temperature creep, and viscosity were tested before and after TFOT. The optimal antiageing content of diatomite was suggested based on the analysis of residual sum of squares (RSS).

\section{Experimental}

2.1. Materials. The asphalt AH-90 used in this paper came from Panjin Petrochemical Industry, Liaoning Province of China. The main physical properties of neat asphalt are given in Table 1. Diatomite was the calcined product from Jilin Province. Its physical properties and particle distribution are shown in Tables 2 and 3, respectively. The mineral powder used is limestone powder, which is used for comparative analysis. Physical properties of limestone powder are shown in Table 4.

2.2. Preparation of Asphalt Mastics. The DA and MA were prepared in laboratory. According to the researches of Cong et al. [12] and Guo et al. [17], four contents $(0 \%, 5 \%, 10 \%$,
TABLE 1: Physical properties of neat asphalt.

\begin{tabular}{lc}
\hline Property & Value \\
\hline Penetration $\left(25^{\circ} \mathrm{C}, 0.1 \mathrm{~mm}\right)$ & 90 \\
Softening point $T_{\mathrm{R} \& \mathrm{~B}}\left({ }^{\circ} \mathrm{C}\right)$ & 42.6 \\
Ductility $\left(15^{\circ} \mathrm{C}, \mathrm{cm}\right)$ & $>100$ \\
Density $\left(15^{\circ} \mathrm{C}, \mathrm{g} / \mathrm{cm}^{3}\right)$ & 1.014 \\
After TFOT & \\
$\quad$ Mass loss $(\%)$ & 0.37 \\
$\quad$ Penetration ratio of $25^{\circ} \mathrm{C}(\%)$ & 59 \\
\hline
\end{tabular}

TABLE 2: Properties of diatomite.

\begin{tabular}{lcccc}
\hline Property & Color & PH & $\begin{array}{c}\text { Specific gravity } \\
\left(\mathrm{g} / \mathrm{cm}^{3}\right)\end{array}$ & $\begin{array}{c}\text { Bulk density } \\
\left(\mathrm{g} / \mathrm{cm}^{3}\right)\end{array}$ \\
\hline Value & Orange & $7 \sim 8$ & $2.1 \sim 2.3$ & $0.35 \sim 0.42$ \\
\hline
\end{tabular}

TABle 3: Particle distribution of diatomite.

\begin{tabular}{lccccc}
\hline $\begin{array}{l}\text { Particle } \\
\text { size }(\mu \mathrm{m})\end{array}$ & $<5$ & $10 \sim 5$ & $20 \sim 10$ & $40 \sim 20$ & $>40$ \\
\hline $\begin{array}{l}\text { Percentage } \\
(\%)\end{array}$ & 62 & 27 & 4.4 & 2.1 & 1.4 \\
\hline
\end{tabular}

and $15 \%$ by the weight of asphalt) were selected in this study. The asphalt mastics were prepared using high-shear homogenizer (KRH-I, Shanghai Konmix Mechanical \& Electrical Equipment Technology Co. Ltd., China) according to [12, 15]. Firstly, diatomite and asphalt were separately placed in the oven at $150^{\circ} \mathrm{C}$ for $4 \mathrm{~h}$ to make sure that the asphalt flowed sufficiently and diatomite reached the blending temperature. Then, diatomite and asphalt were mixed using the high-shear homogenizer with a speed of $4000 \mathrm{rpm}$, and the blending was conducted for 40 minutes at $150^{\circ} \mathrm{C}$ in order to ensure that diatomite is distributed uniformly in asphalt. In case that the mixing process will change the rheological property of asphalt, the neat asphalt should be also processed under the same conditions in order to remove the operational effect. Mixing process is shown in Figure 1.

2.3. Methods. Thin film oven test (TFOT) and rolling thin film oven test (RTFOT) are widely used to simulate the short term oxidative ageing of asphalt $[2,5,7,8,12,20]$. And $\mathrm{Lu}$ and Isacsson [2] indicated that there was a strong correlation between the results of TFOT and RTFOT, and both methods showed very similar severity regardless of the measured parameters. Thus, TFOT was employed to conduct the ageing of mastics in accordance with ASTM D 1754. In this test, the mastic with the amount $50 \mathrm{~g}$ was placed in an iron pan. Then, iron pan was placed on the tray. The axis of revolution was vertical. The ageing was conducted at $163^{\circ} \mathrm{C}$ for $5 \mathrm{~h}$. Process of TFOT is shown in Figure 2.

Softening point is widely used to evaluate high temperature susceptibility of asphalt $[4,21]$. It is the temperature that asphalt could not support the steel ball with the weight $3.5 \mathrm{~g}$ at the heating rate $5^{\circ} \mathrm{C} / \mathrm{min}$ according to ASTM D 36. Increment of softening point $(\Delta T)$ often was used to evaluate the ageing 
TABle 4: Physical properties of mineral powder.

\begin{tabular}{|c|c|c|c|c|c|}
\hline \multirow{2}{*}{ Property } & \multirow{2}{*}{ Hydrophilic coefficient } & \multirow{2}{*}{ Apparent density $\left(\mathrm{g} / \mathrm{cm}^{3}\right)$} & \multicolumn{3}{|c|}{ Gradation } \\
\hline & & & Sieve size $(\mathrm{mm})$ & Passing (\%) & Technical criterion ${ }^{\mathrm{a}}(\%)$ \\
\hline \multirow{3}{*}{ Value } & & & 0.6 & 100 & 100 \\
\hline & 0.77 & 2.742 & 0.15 & 94.4 & $90 \sim 100$ \\
\hline & & & 0.075 & 80.3 & $75 \sim 100$ \\
\hline
\end{tabular}

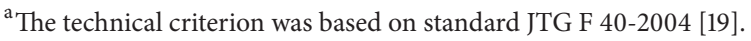

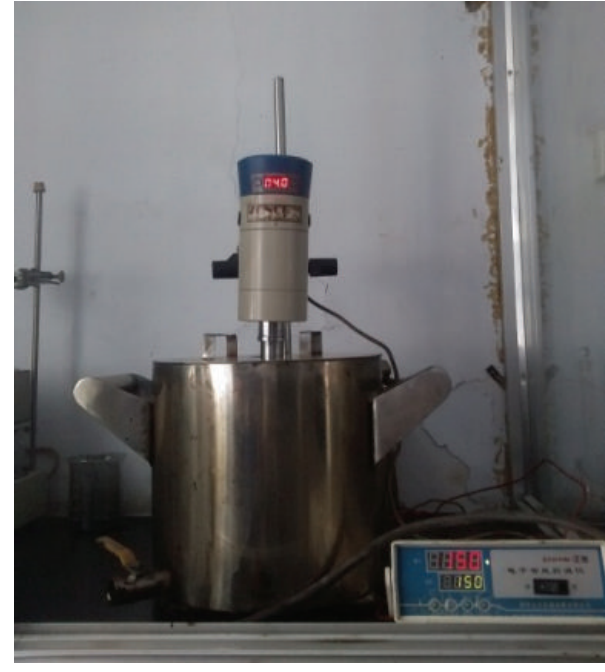

Figure 1: Prepared process of asphalt mastic.

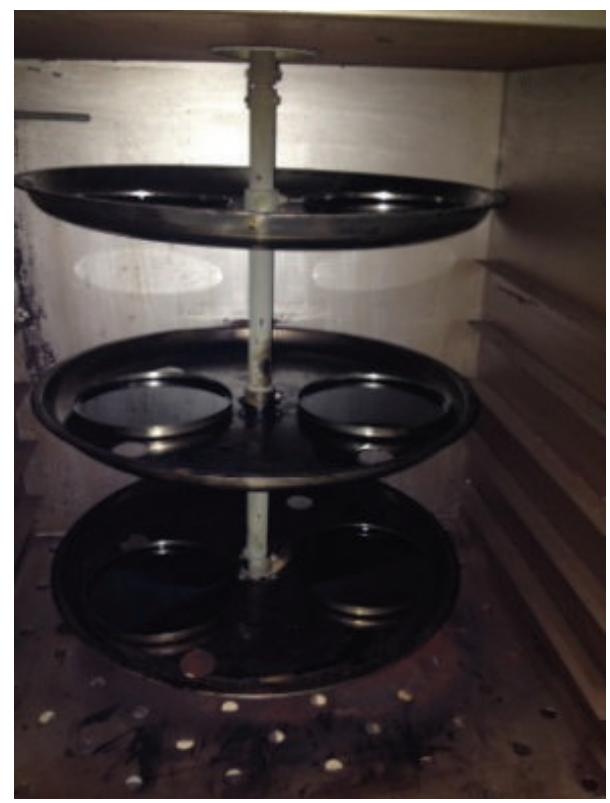

Figure 2: Process of TFOT.

degree $[7,8,12]$, which can be calculated using the following equation:

$$
\Delta T=T_{2}-T_{1}
$$

where $T_{1}$ and $T_{2}$ are the softening points before and after TFOT in this paper, respectively.

Penetration is another important empirical property of asphalt, which is used to evaluate asphalt consistency [5, 21]. Penetrations of asphalt mastics were tested at 15, 25, and $30^{\circ} \mathrm{C}$ according to ASTM D 5 before and after TFOT. Percent retained penetration (PRP) was used to evaluate the antiageing effects of diatomite and mineral powder. PRP can be obtained using the following equation:

$$
\mathrm{PRP}=\frac{P_{2}}{P_{1}} \times 100,
$$

where $P_{1}$ and $P_{2}$ are the penetrations before and after TFOT, respectively.

Force ductility was introduced by Anderson and Wiley [22] at 1976, who thought that asphalt could relax under the loading and possess enough tenacity to maintain a proper matrix. After that, the method was developed and applied to evaluate the tensile property of asphalt and the results indicated that the force ductility test was stable and reliable $[6,23-25]$. Therefore, force ductility test was employed to investigate the tensile cohesive property of asphalt mastics in this paper. The maximum load and force ductility curves were recorded during the test. This test was conducted at $5^{\circ} \mathrm{C}$. The loading rate was $10 \mathrm{~mm} / \mathrm{min}$ because the mastic was breaking so fast that the data could not be recorded effectively under the rate $50 \mathrm{~mm} / \mathrm{min}$. Samples were prepared with the mold of the elastic recovery test in order to produce a test specimen with constant cross section. The maximum force $\left(F_{\max }\right)$, stretched elongation $\left(D_{0 \mathrm{~N}}\right)$, and deformation energy $(J)$ were obtained. During the later stage of testing, the force decreased from $0.5 \mathrm{~N}$ to $0 \mathrm{~N}$, and some samples were still stretched when the displayed force decreased to $0 \mathrm{~N}$. Thus, the force ductility curve could be divided into two parts, as shown in Figure 3. Data of the first part was used to analyze the effect of ageing on tensile cohesive property in this paper.

The ageing effect on tensile cohesive property could be reflected by the ductility retention rate (DRR) and deformation energy ageing index (JAI). These indexes can be calculated with the following equations:

$$
\begin{aligned}
\mathrm{DRR} & =\frac{D_{2}}{D_{1}} \times 100, \\
\mathrm{JAI} & =\frac{J_{\text {aged }}-J_{\text {unaged }}}{J_{\text {unaged }}} \times 100,
\end{aligned}
$$

where $D_{1}$ and $D_{2}$ are the stretched elongation before and after TFOT, respectively, and $J_{\text {unaged }}$ and $J_{\text {aged }}$ are deformation 


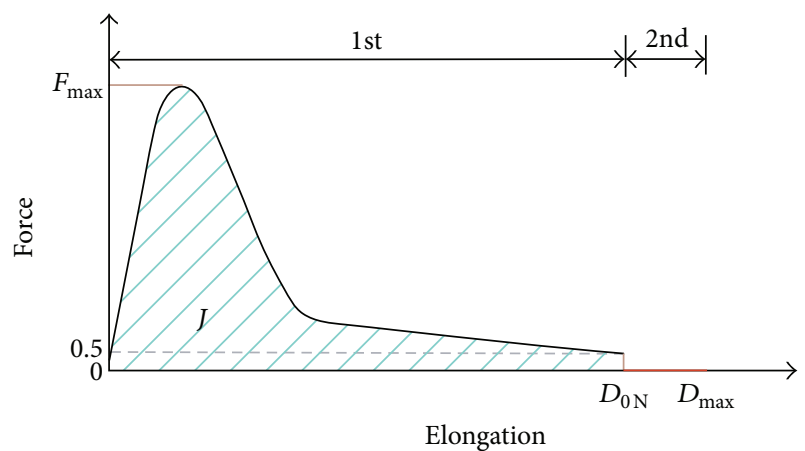

FIGURE 3: Typical force ductility curve.

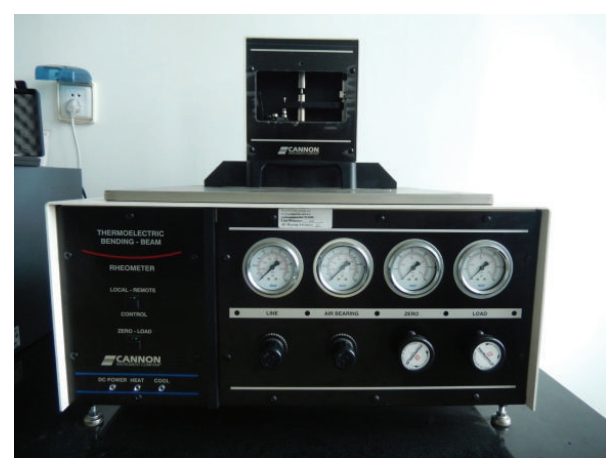

FIGURE 4: Bending beam rheometer (BBR).

energy before and after TFOT, respectively. The greater the JAI is, the more serious the ageing is. The lower the DRR is, the more serious the ageing is.

Bending beam rheometer (BBR) test was an important method developed by the Strategic Highway Research Program (SHRP), which was employed to investigate the low temperature creep property $[6,12,20]$. A bending beam rheometer (TE-BBR, Cannon Instrument Company, USA, as shown in Figure 4) was used to conduct creep tests at $-18^{\circ} \mathrm{C}$. The size of sample is $125 \mathrm{~mm} \times 12.5 \mathrm{~mm} \times 6.25 \mathrm{~mm}$. It was submerged in ethyl alcohol bath at $-18^{\circ} \mathrm{C}$ for $60 \mathrm{~min}$. A constant load of $100 \mathrm{~g}$ was applied to the beam which had been placed on two stainless steel half-rounds ( $102 \mathrm{~mm}$ apart). Deflection of midspan point was measured continuously with a linear variable differential transformer (LVDT). Creep stiffness $(S)$ and creep rate $(m)$ were determined at a loading time of $60 \mathrm{~s}$ according to ASTM D 6648. Besides, the creep stiffness ageing index (SAI) was also developed to evaluate the effect of ageing on low temperature creep stiffness, which could be calculated as follows:

$$
\mathrm{SAI}=\frac{S_{\text {aged }}-S_{\text {unaged }}}{S_{\text {unaged }}} \times 100,
$$

where $S_{\text {unaged }}$ and $S_{\text {aged }}$ are creep stiffness at $-18^{\circ} \mathrm{C}$ before and after TFOT, respectively.

Viscosity was often used to evaluate the shearing deformation resistance of asphalt. And Brookfield viscometer (SD-0625, Shanghai Geology Instrument Institute, China) is widely used to test the viscosity of asphalt due to its simplicity and accuracy $[7,20,21]$. So it was employed in this study. The viscosities at $80,90,100,110,120$, and $130^{\circ} \mathrm{C}$ were tested according to ASTM D 4402. Viscosity ageing index (VAI) was used to evaluate the effect of ageing on shearing resistance of asphalt mastics. The higher the VAI was, the more serious the ageing was [12]. VAI can be calculated by the following equation:

$$
\mathrm{VAI}=\lg \left[\lg \left(\eta_{2} \times 1000\right)\right]-\lg \left[\lg \left(\eta_{1} \times 1000\right)\right],
$$

where $\eta_{1}$ and $\eta_{2}$ are the viscosities before and after TFOT, respectively. For a given content, mean VAI could be obtained using the VAIs at six temperatures in order to analyze the effect of ageing on viscosity.

In addition, activation energy $\left(E_{a}\right)$, which could be used to analyze viscous property of asphalt and mixture, was employed to evaluate the temperature dependency of asphalt mastics [6, 8, 20]. Partal et al. [26] and Ruan et al. [24] suggested that Arrhenius equation could be used to describe the relationship between viscosity and temperature. And $E_{a}$ could be determined with the following equation:

$$
\eta=A \cdot e^{E_{a} / R T},
$$

where $\eta$ is viscosity, $E_{a}$ is activation energy, $R=$ $8.314 \mathrm{~J} \cdot \mathrm{mol}^{-1} \cdot \mathrm{K}^{-1}, T$ is absolute temperature, and $A$ is preexponential factor. Equation (7) was rewritten as the following format in order to determine $E_{a}$ :

$$
\ln \eta=\ln A+\frac{E_{a}}{R T} .
$$

The changing of activation energy during the ageing could be reflected by activation energy ageing index (EAI), which can be expressed as follows:

$$
\mathrm{EAI}=\frac{E_{a, \text { aged }}-E_{a, \text { unaged }}}{E_{a, \text { unaged }}} \times 100 .
$$

\section{Results and Discussion}

3.1. Increment of Softening Point. The softening points of asphalt mastics were tested before and after TFOT in order to estimate the effect of ageing on high temperature stability, and the results are shown in Figure 5.

As shown in Figure 5, the softening point of asphalt mastics linearly increases with the increasing of diatomite and mineral powder content before and after TFOT. It means that high temperature stability of asphalt is improved by diatomite and mineral powder. This tendency is consistent with the results of Cong et al. [12]. The effect of diatomite on softening point is more significant than that of mineral powder according to the regressive slopes. DA has better high temperature stability. This is mainly because that diatomite has a larger volume fraction for its lower density [9], which results in a higher softening point of DA.

As shown in Figure 6, the increment of softening point decreases with the increasing of fillers. And the increments of softening point $(\Delta T)$ of DA are less than that of MA. A great $\Delta T$ indicates a serious thermal oxidative reaction 


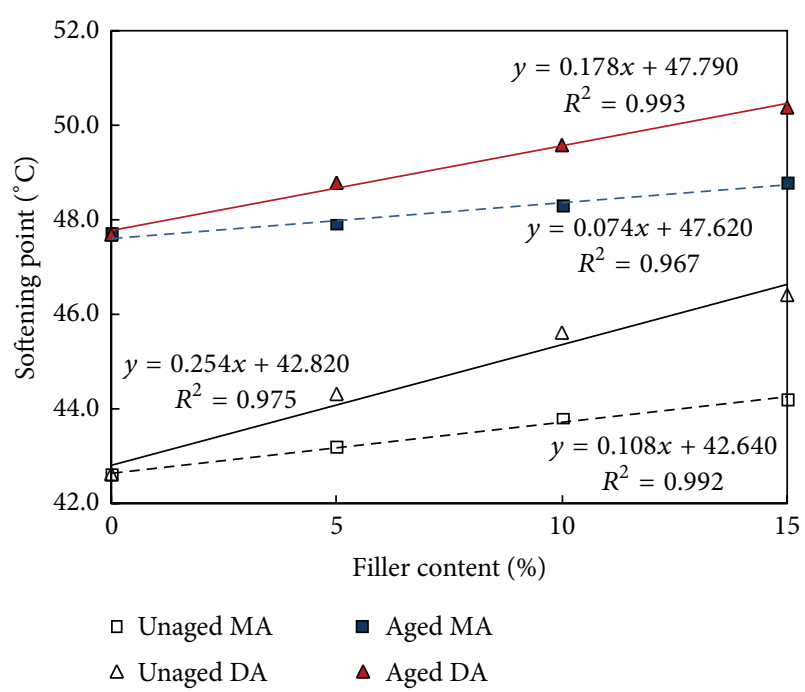

FIGURE 5: Softening points of asphalt mastics versus content before and after TFOT.

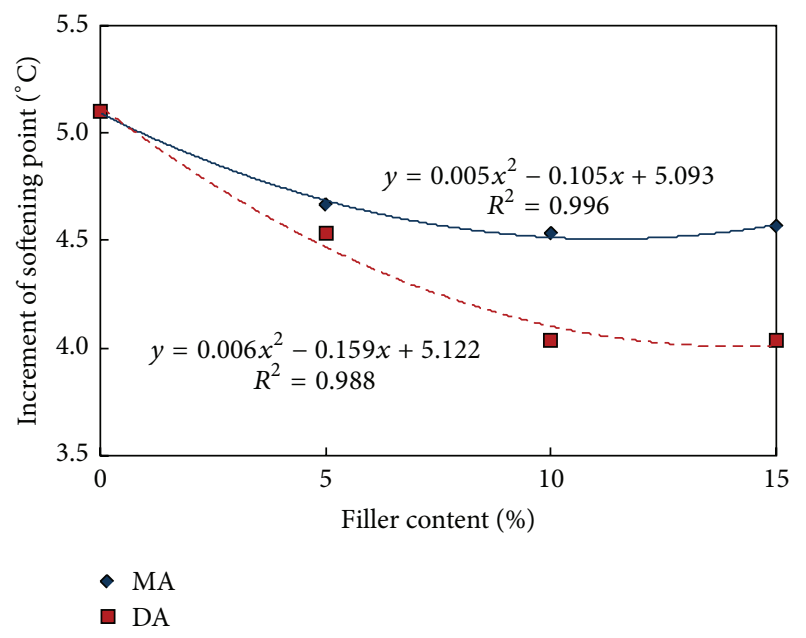

FIGURE 6: Increments of softening point of asphalt mastics versus content after TFOT.

[4]. Therefore, the thermal oxidative reaction of asphalt is reduced by the addition of diatomite and mineral powder. And the antiageing effect of diatomite is better than that of mineral powder. This may be attributed to the difference of internal structure and gradation between mineral powder and diatomite. Qin et al. [18] indicated that the ageing hardening of asphalt was closely correlated and attributed to the compositional changes within asphalts. And Song et al. [13] indicated that diatomite particle could effectively adsorb small molecular group and low polar aromatic molecules of asphalt. So diatomite particle could prevent the contact of molecules group and oxygen, which inhabits the ageing reaction effectively. However, the mineral powder could not adsorb small molecules and low polar aromatic molecules. Therefore, the ageing of MA is more serious than DA.

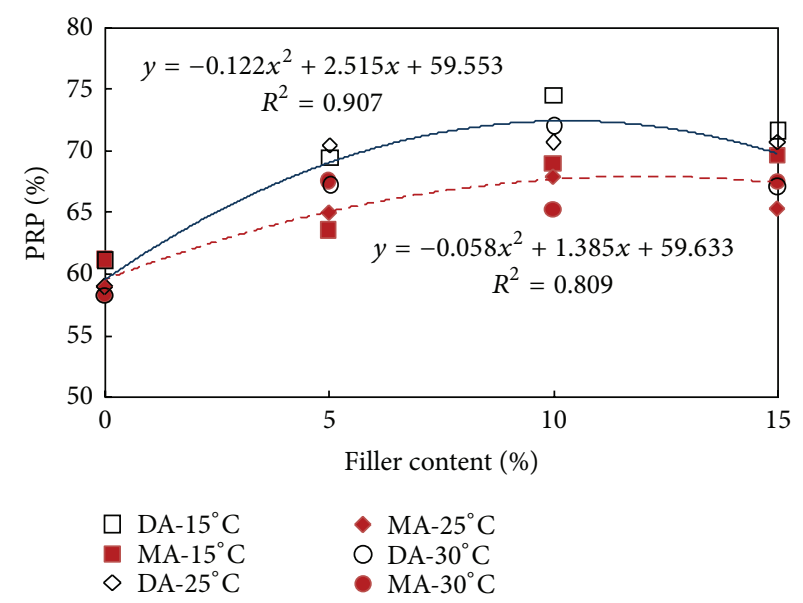

FIGURE 7: PRPs of asphalt mastics versus content after TFOT.

3.2. Percent Retained Penetration (PRP). The penetrations of asphalt mastics were tested at 15,25 , and $30^{\circ} \mathrm{C}$ before and after TFOT in order to investigate the consistency of DA and MA. PRPs were calculated according to (2), and the results are shown in Figure 7.

It can be seen from Figure 7 that PRP increases with the increasing of diatomite and mineral powder content firstly and then it decreases gradually when the mass percentage is greater than $10 \%$. This means that both fillers improve the antiageing effect on penetration. In addition, PRPs of DA are all larger than that of MA. As shown in Figure 7, there are optimal contents for different fillers. The optimal percentages of diatomite and mineral powder are $10.3 \%$ and $12.0 \%$, respectively. Yu et al. [4] had indicated that the higher PRP was, the less ageing reaction was. Therefore, it can be concluded that diatomite has better antiageing effect than mineral powder. And the antiageing property is not linearly improved with the increasing of contents.

3.3. Force Ductility. The force ductility tests were carried out at $5^{\circ} \mathrm{C}$ before and after TFOT in order to evaluate the antiageing effect of diatomite and mineral powder on tensile cohesive property. Results of force ductility tests are listed in Table 5.

As presented in Table 5, $F_{\max }$ 's of DA are all greater than that of MA and the neat asphalt. So DA has higher tensile cohesive failure strength than MA before and after TFOT, due to the fact that diatomite has a larger specific surface area than that of mineral powder, which results in a better cohesive force of DA [13]. $F_{\max }$ 's increase after TFOT, and the maximum increments of $F_{\max }$ are $16.4 \mathrm{~N}$ for MA, $14.5 \mathrm{~N}$ for DA, and $23.7 \mathrm{~N}$ for the neat asphalt. This is caused by the ageing hardening of asphalt $[1,2]$. And the increased values of $F_{\max }$ reflect the ageing degree of different mastics. Thus, the ageing of asphalt is reduced by diatomite and mineral powder. And the inhibition of diatomite on ageing is better than that of mineral powder. Unfortunately, $D_{0 \mathrm{~N}}$ decreases with the increasing of fillers before and after TFOT. It means that diatomite and mineral powder are adverse for deformation 
TABLE 5: Results of force ductility test.

\begin{tabular}{lccccccccc}
\hline \multirow{2}{*}{ Type } & \multirow{2}{*}{ Property } & \multicolumn{4}{c}{ Before TFOT } & \multicolumn{4}{c}{ After TFOT } \\
& & $0 \%$ & $5 \%$ & $10 \%$ & $15 \%$ & $0 \%$ & $5 \%$ & $10 \%$ & $15 \%$ \\
\hline \multirow{3}{*}{ MA } & $F_{\max }(\mathrm{N})$ & 18.1 & 23.1 & 28.4 & 30.4 & 41.8 & 38.9 & 44.8 & 43.1 \\
& $D_{0 \mathrm{~N}}(\mathrm{~mm})$ & 652 & 492 & 515 & 299 & 483 & 360 & 327 & 171 \\
& $J(\mathrm{~N} \cdot \mathrm{mm})$ & 1766 & 2069 & 2329 & 1966 & 2466 & 2586 & 2720 & 2315 \\
\hline \multirow{3}{*}{$\mathrm{DA}$} & $F_{\max }(\mathrm{N})$ & 18.1 & 38.9 & 46.0 & 59.6 & 41.8 & 48.6 & 57.2 & 74.1 \\
& $D_{0 \mathrm{~N}}(\mathrm{~mm})$ & 652 & 526 & 489 & 183 & 483 & 343 & 294 & 107 \\
& $J(\mathrm{~N} \cdot \mathrm{mm})$ & 1766 & 2898 & 3594 & 3509 & 2466 & 3468 & 3780 & 3709 \\
\hline
\end{tabular}

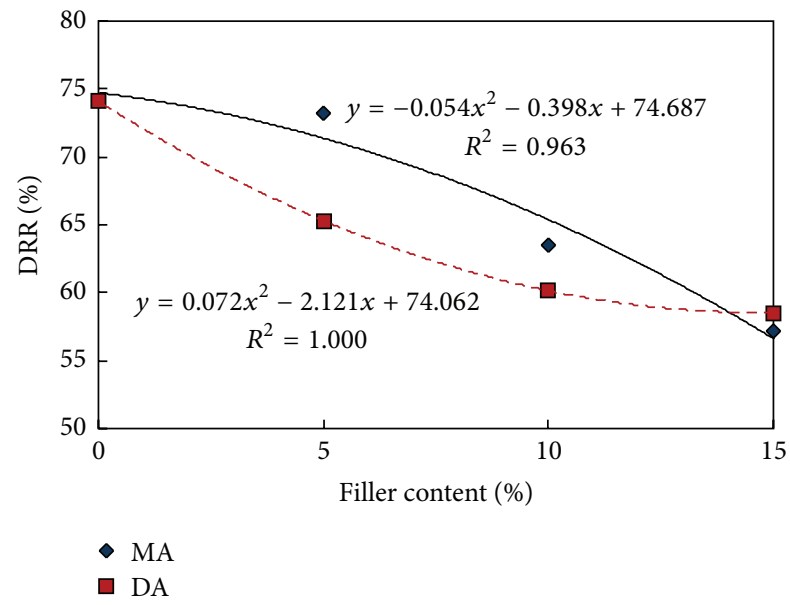

FIGURE 8: DRRs of asphalt mastics versus content after TFOT.

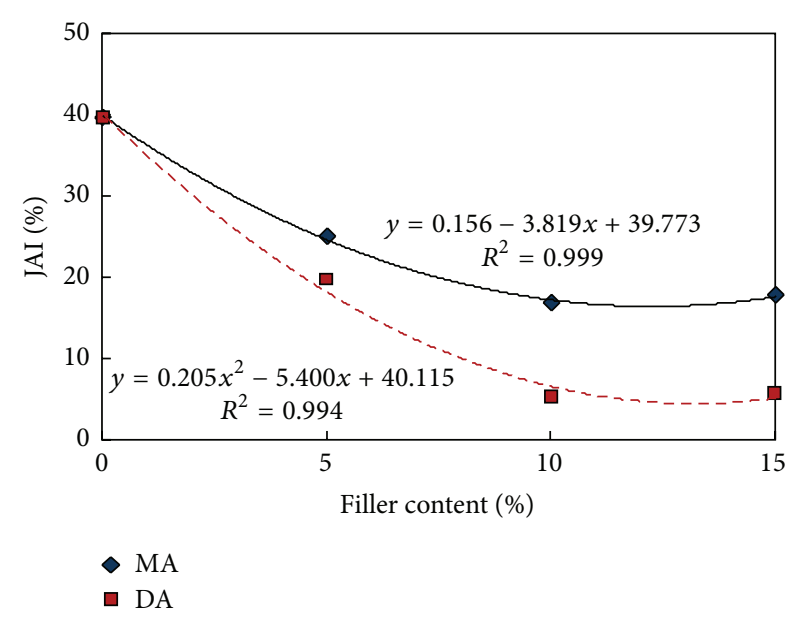

FIGURE 9: JAIs of asphalt mastics versus content after TFOT. performance. In order to evaluate the effect of ageing on ductility, DRR was calculated according to (3), and the results are shown in Figure 8.

As presented in Figure 8, DRR nonlinearly decreases with the increasing of fillers. DRRs of DA are less than that of MA. It means that the aged MA has a better ductility than aged DA after TFOT. Cong et al. [12] and Yi-qiu et al. [15] indicated that the viscosity and stiffness of modified asphalt increased with the increasing of diatomite. And Hesami et al. [27] also suggested that the viscosity of asphalt increased exponentially with the increasing of filler fraction. Zhang et al. [20] indicated that the viscosity and stiffness of asphalt increased after TFOT. So the decline of ductility may be ascribed to the following two reasons. On the one hand, the viscosity and stiffness of neat asphalt increase significantly as a result of thermal oxidative ageing and the blending. The higher the stiffness is, the faster the failure stress reaches. So the increased stiffness causes the failure before asphalt flows under the applied deformation. On the other hand, the volume fraction of diatomite is higher than mineral powder as a result of its low density property. Filler particle blocks the viscoplastic deformation of asphalt at stretching condition. This also results in the decrease of ductility. However, Guo et al. [17] indicated that this disadvantage can be solved by adding fibers in the asphalt mixture.

It can be seen that tensile cohesive failure strength and ductility have different tendencies with the increasing of fillers. Effects of fillers on tensile cohesive property could not be determined by the two indexes directly. So JAI was employed to evaluate the overall antiageing effects of fillers on tensile cohesive property. Results of JAIs are shown in Figure 9.

As shown in Figure 9, JAI nonlinearly decreases with the increasing of fillers. JAIs of DA are less than that of MA. Yu et al. [4] and Edwards et al. [6] indicated that the greater the JAI was, the more serious the ageing was. Therefore, it implies that diatomite has better antiageing effect on tensile cohesive property than mineral powder. The reason can be ascribed to obstruction of diatomite to the ageing hardening process of asphalt.

3.4. Low Temperature Creep. Low temperature creep behavior of asphalt mastics was employed to evaluate the antiageing effect of diatomite and mineral powder on low temperature property using a bending beam rheometer (BBR). Creep stiffness $(S)$ and creep rate $(m)$ were obtained and shown in Figure 10.

The results shown in Figure 10 reveal that creep stiffness $(S)$ of asphalt mastics linearly increases with the increasing of fillers whilst creep rate $(m)$ nonlinearly decreases. Creep stiffness $(S)$ indicates the susceptibility to low temperature cracking as designated by SHRP. The lower $S$ is, the more susceptible the asphalt is. The creep rate $(m)$ represents the change rate of stiffness with loading time, and a high $m$ 


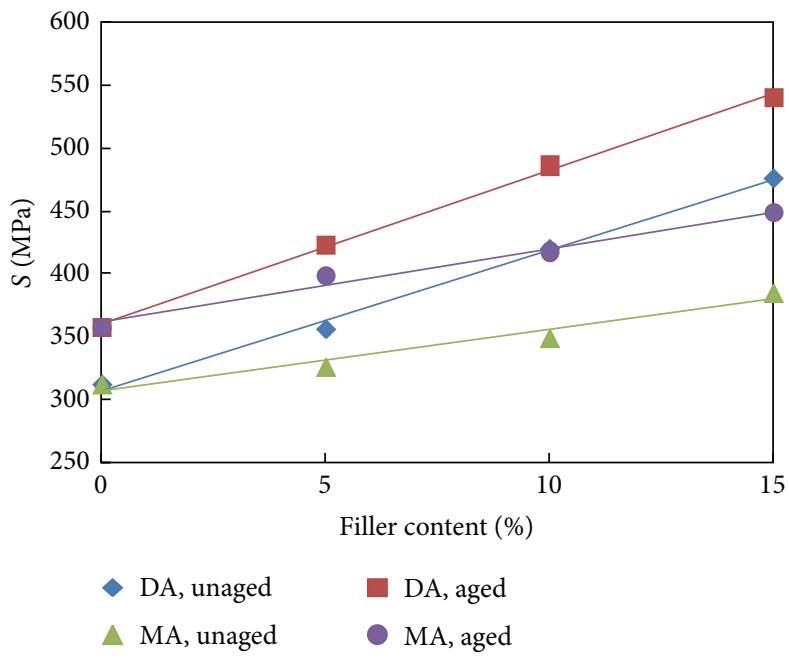

(a)

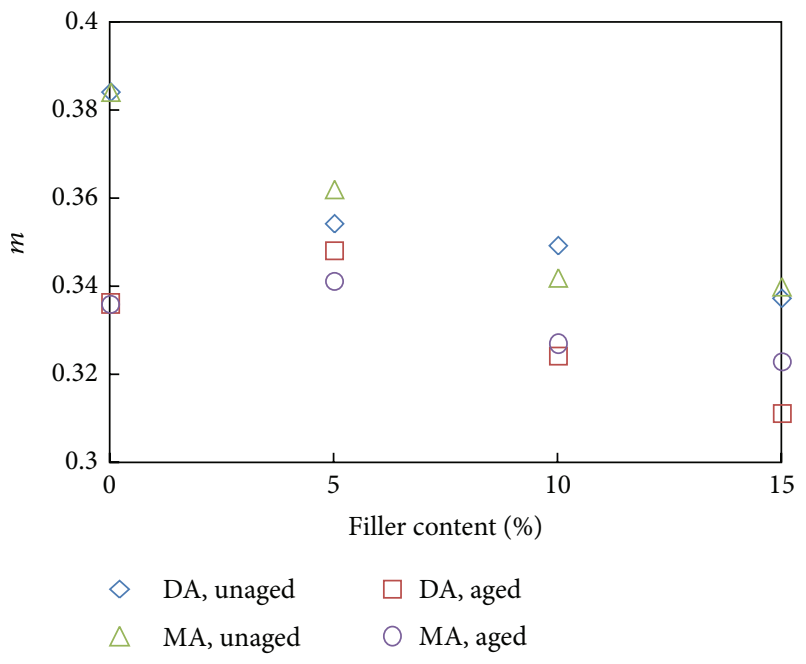

(b)

Figure 10: Results of BBR test before and after TFOT. (a) Creep stiffness $(S)$. (b) Creep rate $(m)$.

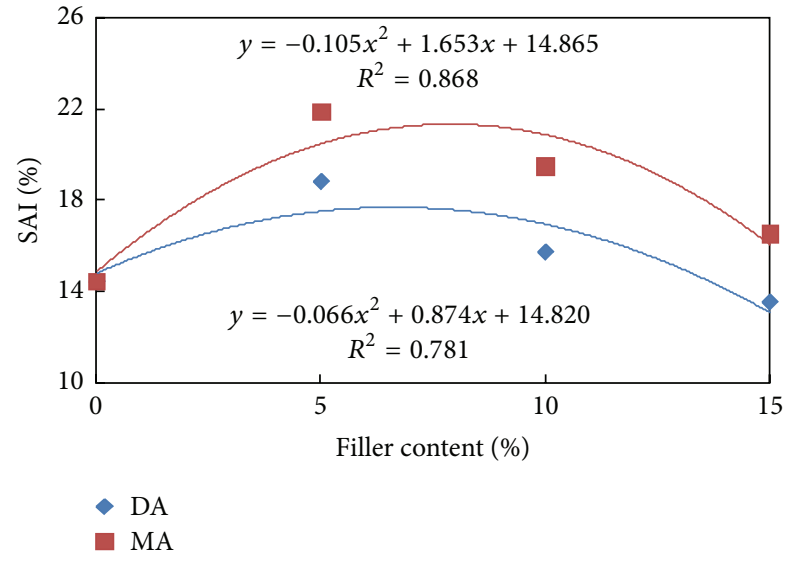

FIGURE 11: SAIs of asphalt mastics versus content after TFOT.

value is desired $[6,12,20]$. Therefore, the DA and MA are more susceptible to low temperature cracking. As shown in Figure 10(a), diatomite has a more significant effect on creep stiffness in comparison with mineral powder. It can be ascribed to the higher volume fraction of diatomite than that of mineral filler. And the $m$ values of DA and MA are differing slightly. Therefore, the low temperature property of asphalt is declined by the addition of diatomite and mineral powder.

In order to analyze the antiageing effect of diatomite and mineral powder on low temperature property of asphalt, the BBR creep stiffness ageing index (SAI) was calculated with (5). Results are shown in Figure 11.

As shown in Figure 11, SAI changes with a convex parabolic tendency versus filler content for both DA and MA. It seems that asphalt mastics aged more seriously when the filler content is less than $10 \%$. The results are opposite to the above ageing indexes. It is possible to be mainly caused by the compound ageing hardening and filler stiffening. And SAIs of DA are less than that of MA, which implies that diatomite has

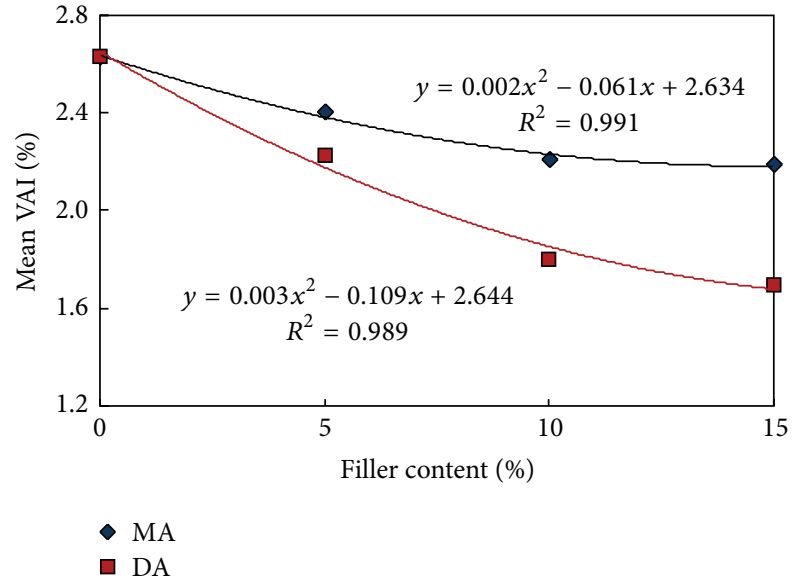

FIGURE 12: Mean VAIs of asphalt mastics versus content after TFOT.

better antiageing effect on low temperature properties than mineral powder.

3.5. Thermal Susceptibility. Viscosity of asphalt increased after ageing. In order to investigate the antiageing effect of diatomite on viscous property, apparent viscosities of asphalt mastics were tested before and after TFOT. VAI was calculated according to (6). Then, mean VAI was obtained for a given content. And it was used to evaluate the effect of ageing on viscosity. The results are shown in Figure 12.

As shown in Figure 12, mean VAIs of DA and MA are all decreased with the increasing of fillers. This implies that both fillers reduce the effect of ageing on viscosities of asphalt. It is consistent with the results obtained by Cong et al. [12]. And mean VAIs of DA are less than that of MA. The lower the VAI is, the better the antiageing property is [12]. Therefore, diatomite more effectively reduces the ageing impact on the viscous property of asphalt than mineral powder. But 
TABLE 6: Results of activation energy $E_{a}$.

\begin{tabular}{lccccccccc}
\hline \multirow{2}{*}{ Type } & \multirow{2}{*}{ Parameter } & \multicolumn{4}{c}{ Before TFOT } & \multicolumn{4}{c}{ After TFOT } \\
& & $0 \%$ & $5 \%$ & $10 \%$ & $15 \%$ & $0 \%$ & $5 \%$ & $10 \%$ & $15 \%$ \\
\hline \multirow{2}{*}{ MA } & $E_{a}(\mathrm{~kJ} / \mathrm{mol})$ & 76.98 & 76.42 & 77.59 & 78.74 & 88.78 & 85.65 & 83.74 \\
& $R^{2}$ & 1.00 & 0.99 & 0.99 & 0.99 & 1.00 & 0.99 & 0.99 & 0.99 \\
\hline \multirow{2}{*}{$\mathrm{DA}$} & $E_{a}(\mathrm{~kJ} / \mathrm{mol})$ & 76.98 & 77.90 & 79.82 & 84.27 & 88.78 & 86.04 & 84.27 & 90.65 \\
& $R^{2}$ & 1.00 & 0.99 & 1.00 & 1.00 & 1.00 & 0.99 & 1.00 & 1.00 \\
\hline
\end{tabular}

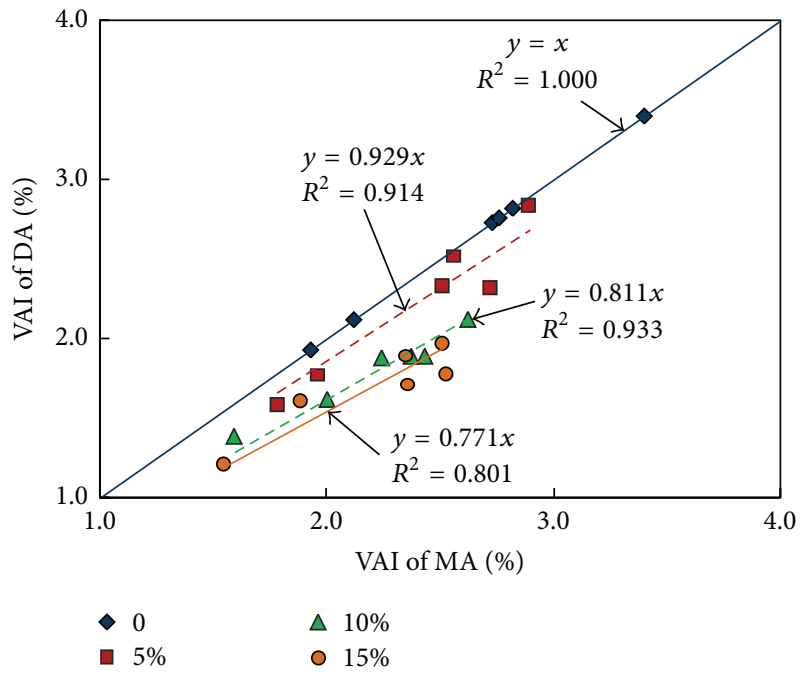

Figure 13: Comparative analysis of VAI.

the quantitative relationship has been yet unclear. So a comparative analysis was conducted in order to determine the difference of DA and MA; the results are shown in Figure 13.

As shown in Figure 13, there are strong linear correlations for VAIs of different mastics when their contents are the same. It means that diatomite and mineral powder have similar antiageing effect on viscosity. It could be also found that VAIs of DA are $0.929,0.811$, and 0.771 times that of MA when their contents are $5 \%, 10 \%$, and $15 \%$, respectively. Therefore, diatomite is better than mineral powder for reducing the ageing effect on viscous property.

In order to evaluate the temperature dependence of asphalt mastic, activation energy $\left(E_{a}\right)$ was determined according to (8), as listed in Table 6.

As presented in Table 6, $E_{a}$ increases with the increasing of fillers. $E_{a}$ 's of aged mastics are all greater than the unaged ones. This tendency agrees with the results of Zhang et al. [20] and Cong et al. [7]. And Cong et al. [7] also indicated that the activation energy $\left(E_{a}\right)$ had a good correlation with the thermal susceptibility of asphalt. The higher $E_{a}$ is, the lower the temperature dependence is. Consequently, the thermal susceptibility of asphalt is improved by diatomite and mineral powder. And the thermal susceptibility of asphalt is also reduced after TFOT. Lu and Isacsson [2] and Ruan et al. [24] indicated that the polar molecules increased and fractions of saturate, aromatic, resin, and asphaltene (SARA) also

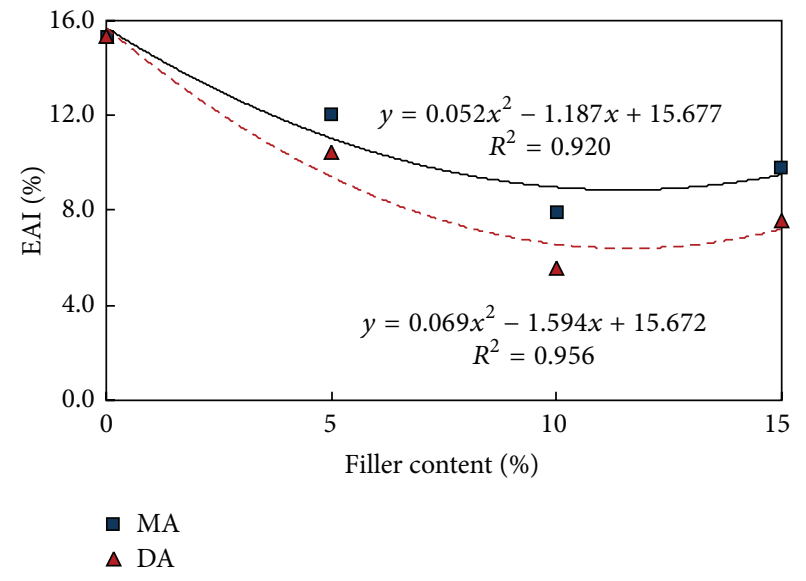

FIgURE 14: EAIs of asphalt mastics versus content after TFOT.

changed after thermal oxidative ageing and volatilization. It resulted in the strong interconnection of internal components and higher flow activation energy of asphalt. Therefore, the larger the activation energy $\left(E_{a}\right)$ is, the more severe the ageing is. In addition, the increments of $E_{a}$ for diatomite and mineral powder are different before and after ageing. Consequently, EAI was used to evaluate the antiageing effects of fillers on $E_{a}$. Results of EAIs are shown in Figure 14.

As shown in Figure 14, $R^{2}$, s are all greater than 0.90, which means that the fittings are reliable. EAI decreases with the increasing of fillers. And EAIs of DA are less than that of MA. It means that the effect of ageing on activation energy $\left(E_{a}\right)$ is reduced by diatomite and mineral powder. So it can be seen that the effect of ageing on the thermal susceptibility of asphalt could be weakened by fillers. And diatomite has a better antiageing effect than mineral powder. The increment of activation energy is adverse for the low temperature performance of asphalt although it is helpful for the reduction of temperature dependence $[7,24,26]$. Thus, the effect of ageing on $E_{a}$ should be reduced as much as possible in order to hold the low temperature property. For this purpose, the smaller the EAI is, the better the antiageing effect of filler is. Therefore, the antiageing effect of diatomite is better than that of mineral powder. The reason is that diatomite prevented the interconnection of internal components of asphalt.

3.6. Optimal Content of Diatomite for Antiageing Purpose. It can be seen that diatomite and mineral powder reduce the effect of oxidative ageing on asphalt effectively. And the effects of diatomite are better than that of mineral powder. So 
TABLE 7: Results of unified optimal content of diatomite.

\begin{tabular}{|c|c|c|c|c|c|}
\hline \multirow{2}{*}{ Property } & \multicolumn{2}{|c|}{ Original } & \multicolumn{2}{|c|}{ After optimization } & \multirow{2}{*}{ Error (\%) } \\
\hline & Optimal content $(\%)$ & Value & Optimal content (\%) & Value & \\
\hline$\Delta T\left({ }^{\circ} \mathrm{C}\right)$ & 14.3 & 4.00 & 12.8 & 4.01 & 0.29 \\
\hline PRP (\%) & 10.3 & 72.53 & 12.8 & 71.76 & 1.05 \\
\hline JAI (\%) & 13.5 & 3.66 & 12.8 & 3.75 & 2.53 \\
\hline VAI (\%) & 18.2 & 1.65 & 12.8 & 1.73 & 4.58 \\
\hline EAI (\%) & 11.6 & 6.49 & 12.8 & 6.58 & 1.38 \\
\hline SAI (\%) & - & 14.82 & 12.8 & 15.16 & 2.29 \\
\hline
\end{tabular}

diatomite can be used to partially replace mineral powder in asphalt mixture in order to improve the antiageing property of mixture. The optimal content of diatomite is needed for engineering application. However, it can be found that the optimal contents of diatomite are different for different properties. This is not convenient for engineering application. Therefore, the method of residual sum of squares (RSS) was used to determine the unified optimal content [28]. $\Delta T, P R P$, JAI, SAI, VAI, and EAI were used for optimal analysis. There is no optimal content for SAI as a result of its convex parabolic tendency. Thus, SAI of the neat asphalt was used as the original value in the optimal analysis. And SAI only was a control index which had not been used in optimal analysis. The unified optimal content can be obtained when the RSS is minimized. RSS can be calculated according to the following equations:

$$
\begin{aligned}
\mathrm{RSS} & =\sum_{i=1}^{5}\left(\frac{y(i, j)-y(i, \text { optimal })}{\Delta y_{i}} \times 100\right)^{2}, \\
\Delta y_{i} & =\mid y(i, \text { optimal })-y(i, 0) \mid,
\end{aligned}
$$

where $y(i, j)$ is the value of $i$ th index for a given content $j$. $y(i$,optimal $)$ is the optimal value of $i$ th index. $\Delta y_{i}$ is absolute different value between $y(i, 0)$ and the optimal value of $i$ th index, and $y(i, 0)$ is the value of neat asphalt in this paper. A program was prepared in order to determine the optimal content of diatomite for antiageing purpose. The step $0.01 \%$ was selected based on the result of trial and error calculating. The results are shown in Table 7.

As listed in Table 7, the unified optimal content is obtained after optimization. All the optimized errors of these indexes are less than $5 \%$ which is required in engineering in general. It means that the optimization of diatomite content is successful and feasible. And this optimal content of diatomite will not result in a great decline of low temperature performance. Therefore, the unified content of diatomite $12.8 \%$ is suggested to be used in engineering in order to improve the antiageing property of asphalt mixture.

\section{Conclusions}

The effects of diatomite and mineral powder on thermal oxidative ageing properties of asphalt were investigated in this paper. The following conclusions were drawn based on the above study.

(i) High temperature stability of asphalt is improved by diatomite and mineral powder. Diatomite particle effectively adsorbs small molecules group and low polar aromatic molecules of asphalt. The ageing reaction of DA is reduced effectively. Resulting in that diatomite has better antiageing effect than mineral powder.

(ii) Low temperature creep property seems to be declined by the addition of diatomite and mineral powder. The ageing hardening and filler stiffening both increase the creep stiffness of neat asphalt, which lead to the higher stiffness ageing index of asphalt mastics than that of neat asphalt. Diatomite has better antiageing effect than mineral powder on low temperature creep property.

(iii) The tensile cohesive failure strength of DA is higher than that of MA. Ductility of DA is less than that of MA. Diatomite has better antiageing effect on tensile cohesive property in terms of the analysis of JAI. The larger specific surface area of diatomite results in a better cohesive force of DA. Thermal oxidative ageing and fillers cause the increasing of viscosity and stiffness. The increased stiffness causes a stress which reaches the failure strength and then leads to the failure of asphalt before flowing. This also reduces the flowing property and ductility.

(iv) The antiageing impact of diatomite on the viscous property of asphalt is more effective than that of mineral powder. The effect of ageing on the thermal susceptibility of asphalt could be weakened by diatomite and mineral powder. Diatomite and mineral powder prevent the interconnection of internal components of asphalt.

(v) Diatomite can be used to partially replace the mineral powder in asphalt mixture in order to improve the antiageing property of mixture. The unified optimal content of diatomite for engineering application can be determined using the method of residual sum of squares (RSS). And the unified content $12.8 \%$ is suggested to be used in asphalt mixture design. 
In summary, the using of diatomite is helpful to improve the antiageing property of asphalt as a result of its porous structure. This will increase the thermal stability of asphalt pavement. The adverse effects of diatomite on ductility and low temperature property should be studied and solved further. And effects of diatomite on long term and in situ ageing should be also noted in future.

\section{Conflict of Interests}

The authors declare that there is no conflict of interests regarding the publication of this paper.

\section{Acknowledgments}

The authors express their appreciation for the financial support of the National Natural Science Foundation of China under Grants nos. 51378236, 51278222, and 51408258; China Postdoctoral Science Foundation funded project (nos. 2014M560237 and 2015T80305); Fundamental Research Funds for the Central Universities and Science (JCKYQKJC06), and Technology Development Program of Jilin Province (20140203002SF).

\section{References}

[1] A. Apeagyei, Development of antioxidant treatments for asphalt binders and mixtures [Ph.D. dissertation], University of Illinois, 2006.

[2] X. Lu and U. Isacsson, "Effect of ageing on bitumen chemistry and rheology," Construction and Building Materials, vol. 16, no. 1, pp. 15-22, 2002.

[3] D. Lesueur, "The colloidal structure of bitumen: consequences on the rheology and on the mechanisms of bitumen modification," Advances in Colloid and Interface Science, vol. 145, no. 1-2, pp. 42-82, 2009.

[4] J. Y. Yu, P. C. Feng, H. L. Zhang, and S. P. Wu, "Effect of organomontmorillonite on aging properties of asphalt," Construction and Building Materials, vol. 23, no. 7, pp. 2636-2640, 2009.

[5] N. Dehouche, M. Kaci, and K. A. Mokhtar, "Influence of thermo-oxidative aging on chemical composition and physical properties of polymer modified bitumens," Construction and Building Materials, vol. 26, no. 1, pp. 350-356, 2012.

[6] Y. Edwards, Y. Tasdemir, and U. Isacsson, "Rheological effects of commercial waxes and polyphosphoric acid in bitumen 160/220-low temperature performance," Fuel, vol. 85, no. 7-8, pp. 989-997, 2006.

[7] P. Cong, J. Wang, K. Li, and S. Chen, "Physical and rheological properties of asphalt binders containing various antiaging agents," Fuel, vol. 97, pp. 678-684, 2012.

[8] P. Pan, S. Wu, Y. Xiao, P. Wang, and X. Liu, "Influence of graphite on the thermal characteristics and anti-ageing properties of asphalt binder," Construction and Building Materials, vol. 68, pp. 220-226, 2014.

[9] M. Reguerio, J. P. Calvo, E. Elizaga, and V. Calderon, "Spanish diatomite geology and economics," Industrial Minerals, vol. 306, pp. 57-67, 1993.

[10] N. Degirmenci and A. Yilmaz, "Use of diatomite as partial replacement for Portland cement in cement mortars," Construction and Building Materials, vol. 23, no. 1, pp. 284-288, 2009.
[11] J. H. Kietzman and C. E. Rodier, "Effect of diatomite filler on performance of asphalt pavements," Transportation Research Record 968, 1984.

[12] P. Cong, S. Chen, and H. Chen, "Effects of diatomite on the properties of asphalt binder," Construction and Building Materials, vol. 30, pp. 495-499, 2012.

[13] Y. Song, J. Che, and Y. Zhang, "The interacting rule of diatomite and asphalt groups," Petroleum Science and Technology, vol. 29, no. 3, pp. 254-259, 2011.

[14] Y. Q. Tan, L. Y. Shan, J. Fang, and X. Y. Zhang, "Anti-cracking mechanism of diatomite asphalt and diatomite asphalt mixture at low temperature," Journal of Southeast University, vol. 25, no. 1, pp. 74-78, 2009 (Chinese).

[15] T. Yi-qiu, Z. Lei, and Z. Xing-you, "Investigation of lowtemperature properties of diatomite-modified asphalt mixtures," Construction and Building Materials, vol. 36, pp. 787-795, 2012.

[16] Y. C. Cheng, H. L. Ma, P. Zhang, J. L. Tao, and J. P. Huang, "Experimental study of physical and mechanical properties of asphalt mortars with different fillers," Jilin Daxue Xuebao (Gongxueban), vol. 6, pp. 1628-1632, 2014 (Chinese).

[17] Q. Guo, L. Li, Y. Cheng, Y. Jiao, and C. Xu, "Laboratory evaluation on performance of diatomite and glass fiber compound modified asphalt mixture," Materials \& Design, vol. 66, pp. 5159, 2015.

[18] Q. Qin, J. F. Schabron, R. B. Boysen, and M. J. Farrar, "Field aging effect on chemistry and rheology of asphalt binders and rheological predictions for field aging," Fuel, vol. 121, pp. 86-94, 2014.

[19] RIOH, "Technical specifications for construction of highway asphalt pavements," JTG F 40-2004, Research Institute of Highway Ministry of Transport, Beijing, China, 2004 (Chinese).

[20] F. Zhang, J. Yu, and S. Wu, "Effect of ageing on rheological properties of storage-stable SBS/sulfur-modified asphalts," Journal of Hazardous Materials, vol. 182, no. 1-3, pp. 507-517, 2010.

[21] M. A. T. Alsheyab and T. S. Khedaywi, "Effect of electric arc furnace dust (EAFD) on properties of asphalt cement mixture," Resources, Conservation and Recycling, vol. 70, pp. 38-43, 2013.

[22] D. I. Anderson and M. L. Wiley, "Force ductility-an asphalt performance indicator," Chemical Abstracts, vol. 45, pp. 25-41, 1976.

[23] Y. Ruan, R. R. Davison, and C. J. Glover, "An investigation of asphalt durability: relationships between ductility and rheological properties for unmodified asphalts," Petroleum Science and Technology, vol. 21, no. 1-2, pp. 231-254, 2003.

[24] Y. Ruan, R. R. Davison, and C. J. Glover, "The effect of long-term oxidation on the rheological properties of polymer modified asphalts," Fuel, vol. 82, no. 14, pp. 1763-1773, 2003.

[25] Y. Yildirim, "Polymer modified asphalt binders," Construction and Building Materials, vol. 21, no. 1, pp. 66-72, 2007.

[26] P. Partal, F. Martínez-Boza, B. Conde, and C. Gallegos, "Rheological characterisation of synthetic binders and unmodified bitumens," Fuel, vol. 78, no. 1, pp. 1-10, 1999.

[27] E. Hesami, D. Jelagin, N. Kringos, and B. Birgisson, "An empirical framework for determining asphalt mastic viscosity as a function of mineral filler concentration," Construction and Building Materials, vol. 35, pp. 23-29, 2012.

[28] M. Melgosa, P. A. García, L. Gómez-Robledo et al., "Notes on the application of the standardized residual sum of squares index for the assessment of intra- and inter-observer variability in color-difference experiments," Journal of the Optical Society of America A, vol. 28, no. 5, pp. 949-953, 2011. 

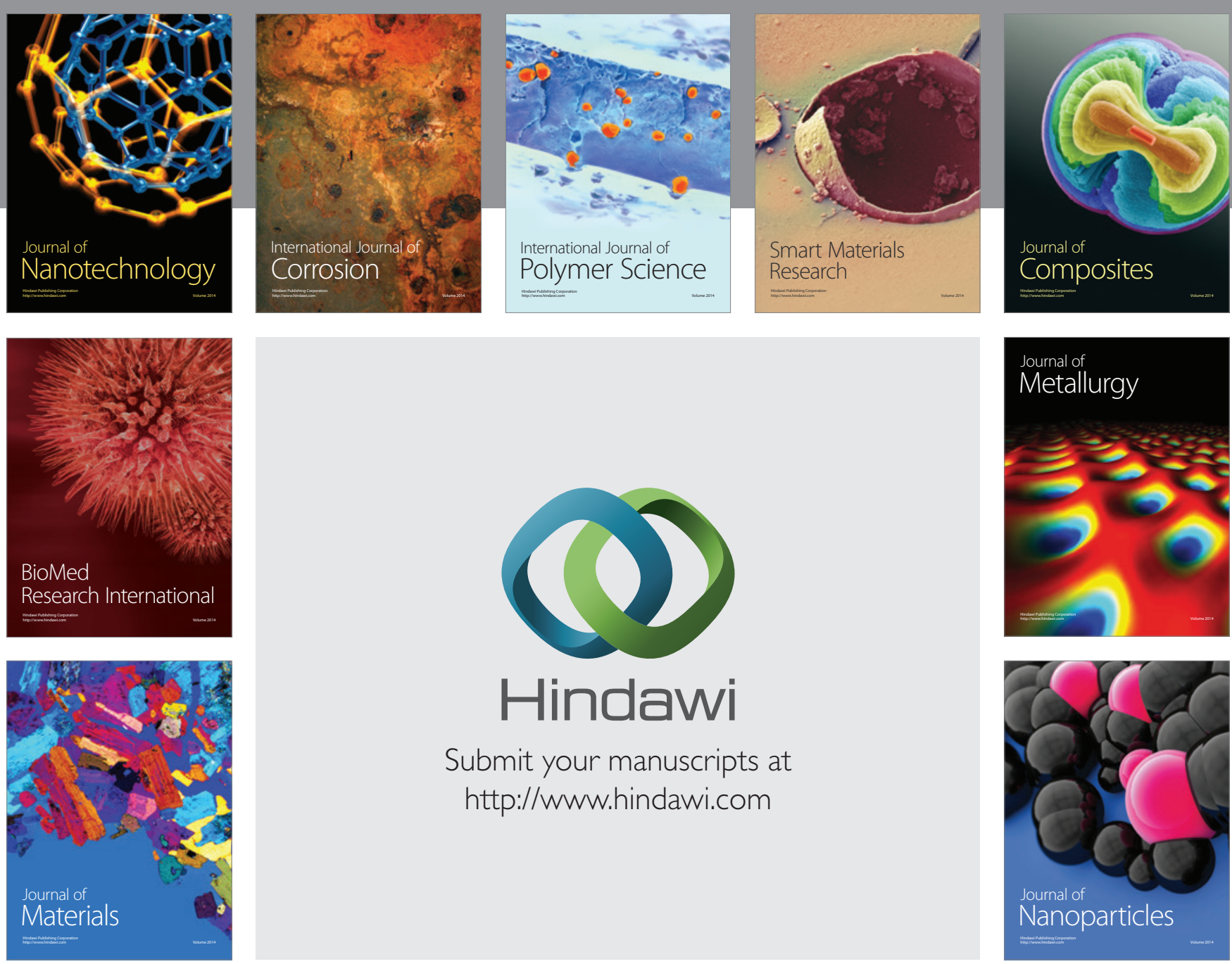

Submit your manuscripts at http://www.hindawi.com
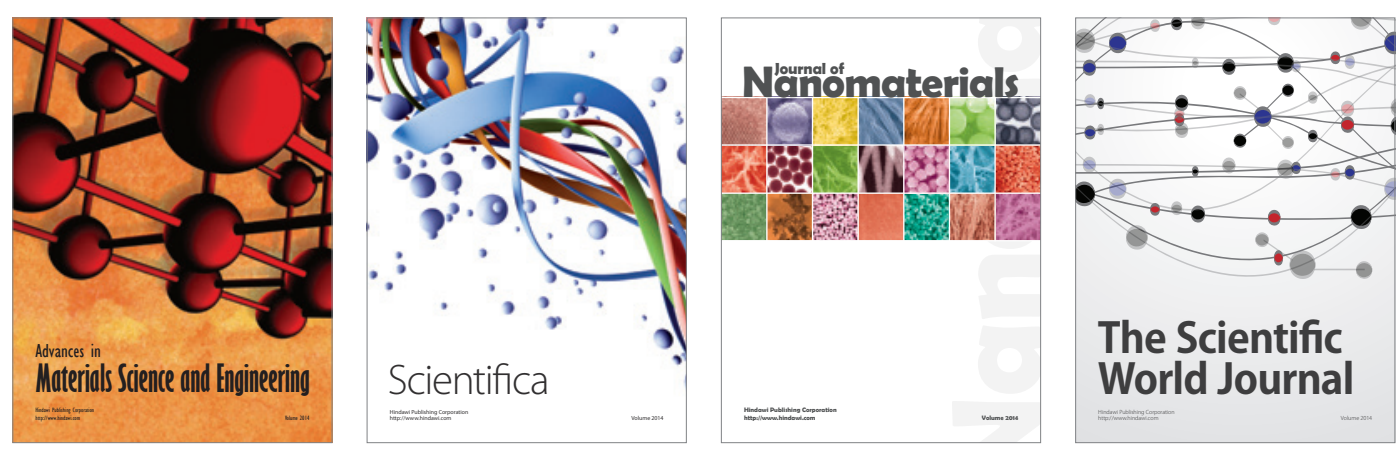

\section{The Scientific World Journal}
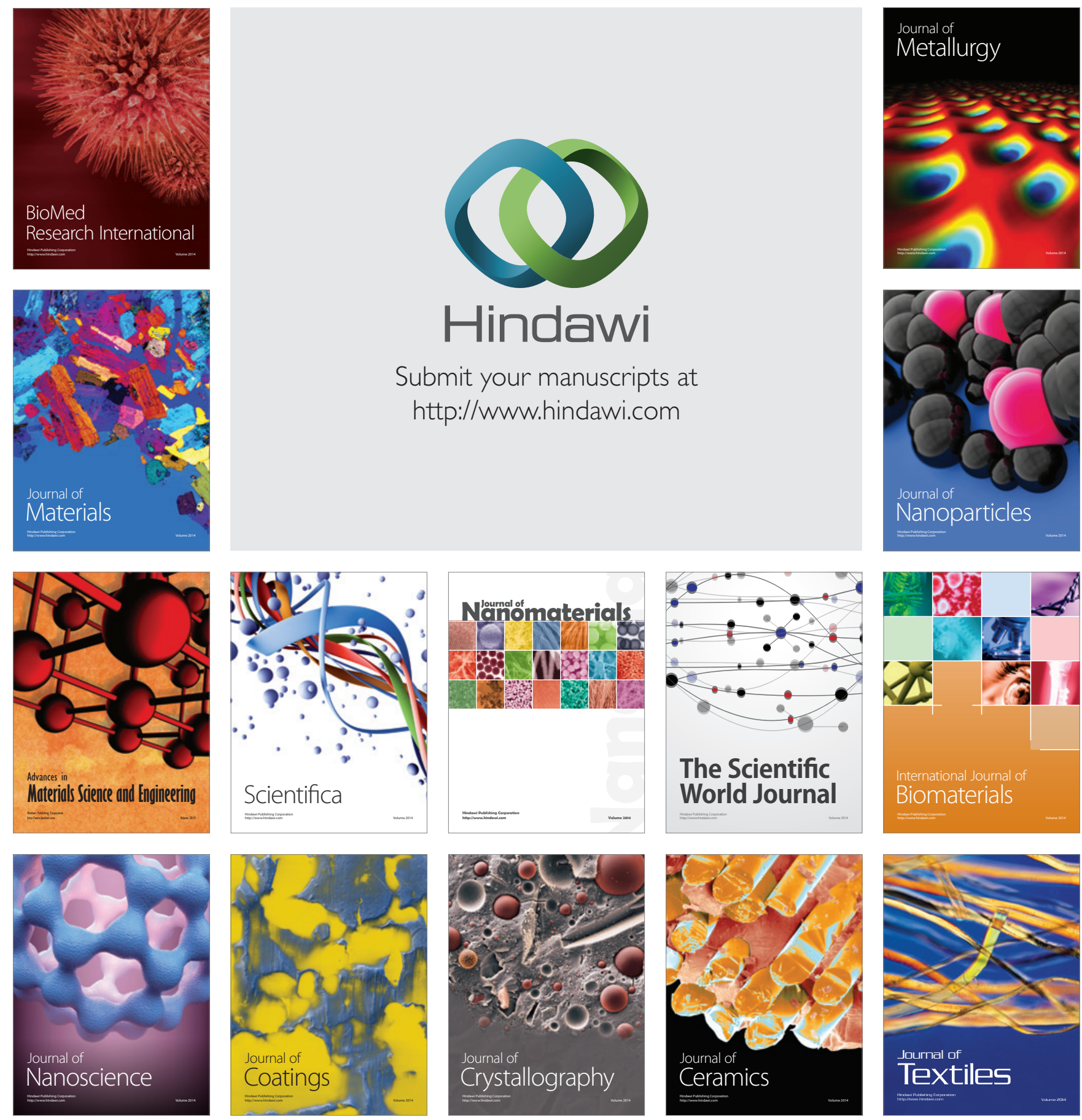